\title{
Impact of late diagnosis and treatment on life expectancy in people with HIV-1: UK Collaborative HIV Cohort (UK CHIC) Study
}

\author{
(c) $\frac{(1)(8)}{\text { ay }}$ OPEN ACCESS
}

\begin{abstract}
Margaret May senior research fellow ${ }^{1}$, Mark Gompels consultant physician, director ${ }^{2}$, Valerie Delpech consultant epidemiologist, head of HIV and AIDS reporting section ${ }^{3}$, Kholoud Porter senior epidemiologist $^{4}$ honorary reader ${ }^{5}$, Frank Post clinical senior lecturer in HIV medicine ${ }^{6}$, Margaret Johnson professor and consultant physician of general medicine, HIVIAIDS, and thoracic medicine ${ }^{7}$, David Dunn biostatistician ${ }^{4}$, Adrian Palfreeman consultant in genitourinary medicine ${ }^{8}$, Richard Gilson consultant physician and senior clinical lecturer ${ }^{9}$, Brian Gazzard professor of medicine and director of HIV clinical research ${ }^{10}$, Teresa Hill research fellow ${ }^{5}$, John Walsh consultant in HIV and sexual health ${ }^{11}$, Martin Fisher consultant physician in HIV and genitourinary medicine ${ }^{12}$, Chloe Orkin consultant HIV physician ${ }^{13}$, Jonathan Ainsworth consultant HIV physician ${ }^{14}$, Loveleen Bansi research statistician $^{5}$, Andrew Phillips professor of epidemiology ${ }^{5}$, Clifford Leen honorary professor of medicine, consultant physician in infectious diseases ${ }^{15}$, Mark Nelson consultant physician ${ }^{10}$ senior lecturer ${ }^{16}$, Jane Anderson consultant physician, director of the centre for the study of sexual health and HIV ${ }^{17}$, Caroline Sabin professor of medical statistics and epidemiology ${ }^{5}$
\end{abstract}

\footnotetext{
${ }^{1}$ School of Social and Community Medicine, Bristol University, Bristol BS8 2PS, UK; ${ }^{2} \mathrm{HIV}$ Service, North Bristol NHS Trust, Bristol; ${ }^{3} \mathrm{HIV}$ and STI Department, Health Protection Services, Health Protection Agency, London; ${ }^{4}$ Medical Research Council Clinical Trials Unit, London; ${ }^{5}$ University College London, London; ${ }^{6}$ King's College London, London; ${ }^{7}$ Royal Free Hospital NHS Trust, London; ${ }^{8}$ Leicester Royal Infirmary, Leicester; ${ }^{9} \mathrm{UCL}$ Centre for Sexual Health and HIV Research, Mortimer Market Centre, London; ${ }^{10}$ Chelsea and Westminster Hospital, London.; ${ }^{11}$ Imperial College Healthcare Trust, London; ${ }^{12}$ Brighton and Sussex University Hospitals, Brighton; ${ }^{13}$ Barts and The London School of Medicine and Dentistry, London; ${ }^{14}$ North Middlesex University Hospital, London; ${ }^{15}$ Western General Hospital, Edinburgh; ${ }^{16} \mathrm{Imperial}$ College School of medicine, London; ${ }^{17} \mathrm{Homerton}$ University Hospital NHS Foundation, London
}

\author{
Abstract \\ Objectives To estimate life expectancy for people with HIV undergoing \\ treatment compared with life expectancy in the general population and \\ to assess the impact on life expectancy of late treatment, defined as \\ CD4 count $<200$ cells $/ \mathrm{mm}^{3}$ at start of antiretroviral therapy. \\ Design Cohort study. \\ Setting Outpatient HIV clinics throughout the United Kingdom. \\ Population Adult patients from the UK Collaborative HIV Cohort (UK \\ CHIC) Study with CD4 count $\leq 350$ cells $/ \mathrm{mm}^{3}$ at start of antiretroviral \\ therapy in 1996-2008.
}

\begin{abstract}
Main outcome measures Life expectancy at the exact age of 20 (the average additional years that will be lived by a person after age 20), according to the cross sectional age specific mortality rates during the study period.

Results 1248 of 17661 eligible patients died during 91203 person years' follow-up. Life expectancy (standard error) at exact age 20 increased from 30.0 (1.2) to 45.8 (1.7) years from 1996-9 to 2006-8. Life expectancy was $39.5(0.45)$ for male patients and $50.2(0.45)$ years for female patients compared with 57.8 and 61.6 years for men and women in the general population (1996-2006). Starting antiretroviral therapy later than guidelines suggest resulted in up to 15 years' loss of life: at
\end{abstract}


age 20, life expectancy was 37.9 (1.3), 41.0 (2.2), and 53.4 (1.2) years in those starting antiretroviral therapy with CD4 count $<100,100-199$, and 200-350 cells $/ \mathrm{mm}^{3}$, respectively.

Conclusions Life expectancy in people treated for HIV infection has increased by over 15 years during 1996-2008, but is still about 13 years less than that of the UK population. The higher life expectancy in women is magnified in those with HIV. Earlier diagnosis and subsequent timely treatment with antiretroviral therapy might increase life expectancy.

\section{Introduction}

HIV infection has become a chronic disease with a good prognosis provided treatment is started sufficiently early in the course of the disease and the patient is able to maintain lifelong adherence to antiretroviral therapy. ${ }^{12}$ Mortality rates have decreased such that, compared with the general population, the risk of death in successfully treated patients is similar to that of people with unhealthy lifestyles (such as heavy smoking, drinking, or obesity) or other chronic conditions such as diabetes. ${ }^{3}$ Although previous studies have compared mortality rates in patients with HIV with those in the general population ${ }^{3-6}$ or have reported the prognosis of patients with HIV by estimating cumulative probability of death, ${ }^{7}$ few have estimated how long those with HIV are likely to live.

Estimates of life expectancy are important to individuals who want to plan their lives better, to service providers, and to policy makers. Patients might use this information to inform decisions on when they start antiretroviral therapy and treatment of comorbidities, pension provision, starting a family, or buying a house. Service providers require estimates of life expectancy to project the number of people with HIV who will need treatment and the future costs of providing antiretroviral therapy. Policy makers in the health service will be interested in addressing inequalities in life expectancy between patients with different characteristics, such as race or sex, or between those with early or delayed initiation of antiretroviral therapy. ${ }^{8}$

Life expectancy in the general population varies by age, sex, and race, ${ }^{9}$ and there are substantial differences between low and high income countries, which are reflected in different mortality rates in people with HIV. ${ }^{10}$ Furthermore, the pattern of the HIV epidemic varies by country. ${ }^{11}$ Life expectancy in populations with HIV has been estimated in specific countries ${ }^{12-15}$ and in collaborations of cohorts ${ }^{6}{ }^{16}$ but not in the United Kingdom.

We estimated life expectancy in those treated for HIV infection and compared this with the life expectancy of the general population in the UK using data from the UK Collaborative HIV Cohort (UK CHIC) Study ${ }^{11}$ for 1996-2008. We also estimated the loss in life expectancy of those who start antiretroviral therapy at a more advanced stage of the disease than recommended by national treatment guidelines and quantified the potential years of life lost as a measure of the burden of HIV disease at the population level in the UK.

\section{Methods}

\section{Cohort description}

The UK CHIC Study started in 2001 and collates routine data on people with HIV attending some of the largest clinical centres in the UK from 1 January 1996 (see appendix 1 on bmj.com). In accordance with the data protection policy, data were provided in an anonymised format with all names removed and replaced by first name initial and a soundex code derived from the patient's surname. To be included in the UK CHIC Study people had to be positive for HIV infection, have attended one of the collaborating centres at any time since 1996, and be aged 16 or over. ${ }^{11}$

\section{Selection of patients}

Patients included in this analysis were all aged 20 and over and had started treatment with antiretroviral therapy with at least three drugs between 1 January 1996 and 31 December 2008. We excluded patients with incomplete data on demographic variables (age, sex, and ethnicity) and those whose assumed transmission was through use of injected drugs because of the low prevalence and worse prognosis compared with other risk groups. We also excluded patients who started antiretroviral therapy with a recorded CD4 cell count $>350$ cells $/ \mathrm{mm}^{3}$ as current UK treatment guideline $\mathrm{s}^{17}$ recommend that treatment should be started at below this threshold in people with asymptomatic HIV infection, and treatment at higher CD4 counts is generally recommended only for specific subgroups of patients (such as pregnant women, those with symptomatic infection or other comorbidities) whose outcomes might be expected to differ. Patients with missing baseline CD4 count were included in the study population. Patients were followed up from start of antiretroviral therapy for all cause mortality, which was ascertained from clinic records and by linkage to national surveillance data on deaths.

\section{Statistical methods}

We calculated crude mortality rates (per 1000 person years) for all ages and for individuals aged 20-44. Potential years of life lost ${ }^{18}$ were calculated as the sum of years lost because of premature death; this was defined as death before age 65 , which is the age at which most people retire in the UK. Potential years of life lost were expressed per 1000 person years from age 20 to 64. Abridged life tables were constructed from age specific mortality rates grouped in five year age bands to estimate life expectancy from the age of 20 to 65 . These tables describe the mortality experience that hypothetical cohorts of people with HIV would have had if they were subjected to the mortality in the observed period. Life expectancy at an exact age is the average additional years that will be lived by a person after that age, according to the cross sectional age specific mortality rates for all causes during the study period.

Mortality rates for the open age grouping $(\geq 65)$ could not be meaningfully estimated because there were too few older patients to allow further stratification by age. Therefore the rate of death in those aged $\geq 65$ was adjusted by using the rate ratio of mortality in the HIV positive population to that of the UK population. We assumed that the rate ratio in those aged $\geq 65$ was the same as the average rate ratio of the 55-59 and 60-64 age groups. We estimated rate adjustments separately for each period in the analysis: these were $5.69,2.76,2.73$, and 2.01 for 1996-9, 2000-2, 2003-5, and 2006-8, respectively. The overall rate adjustment for 1996-2008 was 2.56, and we used this value to adjust other analyses that were not divided by period of follow-up. We investigated the sensitivity of estimates of life expectancy over the period 1996-2008 to the adjustment used by varying the rate adjustment from 1 (no adjustment) to 6 .

Health indicators were calculated overall and stratified by calendar period of follow-up (1996-9, 2000-2, 2003-5, 2006-8), sex, CD4 count measured in the three months before starting antiretroviral therapy $\left(0-99,100-199,200-350\right.$ cells $\left./ \mathrm{mm}^{3}\right)$, and the period in which antiretroviral therapy was started. The analysis stratifying by CD4 included patients who started treatment after 2000 and had no previous exposure to antiretroviral drugs before starting antiretroviral therapy with 
three or more drugs so that the results should be applicable to patients who currently start treatment. Patients without a CD4 count recorded at start of antiretroviral therapy were excluded from this analysis. Initiation of antiretroviral therapy was the start of follow-up for all analyses and is denoted as the "baseline." As the highest mortality rate was in the first six months of antiretroviral therapy, we repeated the calculations restricting analyses to those who survived at least six months after starting treatment. We also investigated whether life expectancy varied by ethnicity and sex (white men, non-white men, white women, non-white women). For comparison, we calculated health indicators for men and women in the UK population using data from 1996 to 2006. Number of deaths and person years at risk were extracted from the website www. mortality.org in five year age bands. Detailed information on the calculation of life tables and potential years of life lost have been published previously. ${ }^{16}$ Analyses were done with Stata version 11 and Microsoft Excel 2008.

\section{Results}

The UK CHIC Study included data on 35377 people with HIV, of whom 22876 started antiretroviral therapy in 1996-2008. We excluded one patient with missing age and 315 who were aged under 20, $820(4 \%)$ with an assumed risk transmission through use of injected drugs, 3137 (14\%) known to have started antiretroviral therapy with a CD4 count above the recommended treatment threshold of 350 cells $/ \mathrm{mm}^{3}, 743$ (3\%) with missing ethnicity, and 199 with no follow-up time recorded. This left 17661 patients eligible for inclusion in the analyses.

Table $1 \Downarrow$ shows the characteristics of patients at baseline by the period in which they started antiretroviral therapy and overall. The proportions of white people, men, and men who have sex with men were higher in 1996-9 compared with later periods. Compared with later periods, patients who started antiretroviral therapy in 1996-9 were more immunosuppressed and were more likely to have had a diagnosis of AIDS. Patients had a median follow-up of 5.1 (interquartile range 2.2-8.9) years. During the 91203 person years of follow-up 1248 (7\%) patients died.

Table $2 \Downarrow$ shows the time trends in health indicators by period of follow-up. Life expectancy at the exact age of 20 increased by nearly 16 years from $1996-9$ to $2006-8$, and there was a linear trend $(\mathrm{P}<0.001)$ across period of follow-up for overall mortality and mortality at age 20-44. For a hypothetical cohort of patients starting antiretroviral therapy at age 20 and experiencing the age specific death rates observed during 1996-9, the proportion surviving to age 45 would have been slightly over $60 \%$. This figure increased to over $80 \%$ when we used the death rates experienced from 2003 onwards. During these years there was a corresponding shift in the distribution of measurements of CD4 counts (fig $1 \Downarrow$ ). Each measurement was included as an independent observation and assigned to the relevant period of follow-up (the frequency of CD4 monitoring did not change greatly over the study period). In $1996-9,38 \%$ of measurements were $<200$ cells $/ \mathrm{mm}^{3}$ and $34 \%$ were $>350$ cells $/ \mathrm{mm}^{3}$, whereas in $2006-8$ the proportions were $12 \%$ and $65 \%$, respectively.

Table $3 \Downarrow$ shows the life expectancy for men and women with HIV undergoing treatment during the study period and, for comparison, the life expectancy of the UK population. Compared with the same sex in the general UK population, for patients undergoing treatment for HIV infection, life expectancy at age 20 was 18.3 years less for men and 11.4 years less for women. Compared with men, the life expectancy of women was greater by just less than four years, but this difference is magnified in those treated for HIV, where the gap was over 10 years.
To show the potential effect of late treatment on life expectancy, we estimated health indicators stratified by CD4 count for patients who had not previously received any antiretroviral drugs and started therapy with three or more drugs after 2000, when non-nucleoside reverse transcriptase inhibitors were widely available. Out of 11812 patients who started antiretroviral therapy in 2000-8, $664(6 \%)$ were pre-treated with one or two drugs and were not eligible for inclusion. Of the 11148 eligible patients, 9657 (87\%) had a CD4 count recorded at baseline and were included in the analysis. Figure $2 \Downarrow$ shows life expectancy between the ages of 20 and 65 in those with HIV stratified by CD4 count compared with the life expectancy of men and women in the UK population. Table $4 \Downarrow$ shows that life expectancy decreased by over 10 years in those starting antiretroviral therapy with CD $4<200$ cells $/ \mathrm{mm}^{3}$ compared with 200-350 cells $/ \mathrm{mm}^{3}$. The population impact of premature mortality before the age of 65 is illustrated by the difference in potential years of life lost, which increased by a factor of three for patients who started with CD $4<100$ cells $/ \mathrm{mm}^{3}$ compared with 200-350 cells $/ \mathrm{mm}^{3}$, an absolute difference of 237 years lost per 1000 person years (24\%). If we compare this with the UK population estimates shown in table 3 , the difference in potential years lost is about 9\%, 15\%, and 33\% for those who start antiretroviral therapy with a CD4 count 200-350, 100-199, and $<100$ cells $/ \mathrm{mm}^{3}$, respectively $\Downarrow$. As the life expectancy for the general UK population (weighted by the sex proportion of the HIV positive cohort) is about 58.8 years at the exact age of 20 , the loss in life expectancy from the high to low CD4 groups is $5.4,17.8$, and 20.9 years, respectively. Of note, 5895 out of $14001(42 \%)$ patients in UK CHIC had a CD4 count <200 cells $/ \mathrm{mm}^{3}$ within three months of diagnosis.

In sensitivity analyses that varied the adjustment to rate of death in the open age group $(\geq 65)$, the life expectancy at the exact age of 20 varied from 49.8 (no adjustment) to 37.9 for a rate ratio of 6 (maximum adjustment considered). We estimated this life expectancy to be 41.1 years (see table 2), using the observed average rate ratio in the 55-59 and 60-64 groups, which was 2.56. For comparison, life expectancy was 42.7 and 40.3 years with 2 and 3 as plausible limits of the rate ratio adjustment.

We found little evidence of a difference in life expectancy between white and non-white groups once sex had been accounted for, but estimates were imprecise because of imbalances in the distribution of ethnicity by sex and the heterogeneous nature of the non-white group. We also found that restricting analyses to those who survived at least six months after starting antiretroviral therapy improved life expectancy at age 20 (overall for period 1996-2008) by less than two years. We repeated analyses stratifying by period of starting antiretroviral therapy instead of period of follow-up, omitting 2005-8 as there was insufficient follow-up for patients starting treatment in the most recent years. As expected, we found a similar strong trend of improvement in health indicators over the first three calendar periods (see appendix 2 on bmj.com).

\section{Discussion}

The life expectancy of people with HIV treated with antiretroviral therapy in UK hospital clinics has substantially increased over the period 1996-2008, but remains much lower than that of the UK population. Women have a higher life expectancy than men, which is only partially accounted for by sex differences in the life expectancy of the background population. Most importantly, life expectancy is strongly related to the CD4 count at which individuals start treatment. Patients who were diagnosed late or deferred treatment until their CD4 
count fell to below 200 cells $/ \mathrm{mm}^{3}$ were estimated to have a life expectancy at age 20 at least 10 years less than those who conformed to current treatment guidelines, which suggest that patients should start antiretroviral therapy once their CD4 count has fallen below 350 cells $/ \mathrm{mm}^{3} .{ }^{17}{ }^{19}$ Furthermore, the effect of delayed diagnosis and treatment is worse than our results suggest as some people die without ever starting antiretroviral therapy. This highlights the need to identify people infected with HIV early in the course of their infection, before substantial CD4 loss has occurred.

\section{Strengths and limitations of study}

In the UK in 2008 an estimated 45893 people with HIV were receiving antiretroviral therapy. ${ }^{20}$ We included 17661 individuals in our analyses (about $38 \%$ of all treated patients) and therefore results should be broadly applicable to a population of people with HIV who start antiretroviral therapy with a CD4 cell count below 350 cells $/ \mathrm{mm}^{3}$ in the UK. Although our findings might not be generalisable to settings other than the UK, they will contribute to comparisons of life expectancy across different settings. Our results do not apply to untreated patients or those infected with HIV who have yet to receive a diagnosis or access care. We excluded patients with a history of use of injected drugs as they have higher mortality, particularly if they also have hepatitis B or C, and we were unable to analyse drug users separately as numbers were too small. There might have been some misclassification of users of injected drugs as the dataset includes information only on the most likely route of HIV infection rather than ongoing injected drug use; however, we believe that any misclassification is likely to be small.

The estimates of life expectancy could be biased upwards because of under-ascertainment of deaths, but regular attempts are made to minimise this through the triangulation of information on deaths held by the UK CHIC Study, surveillance studies from the Health Protection Agency Centre for Infections, and the death registry of the Office for National Statistics (ONS). Furthermore, through anonymous linkage of data from patients thought to be attending more than one clinic, regular attempts are made to ensure that the denominator of patients under follow-up is accurate and that loss to follow-up is minimised. ${ }^{21}$ This is particularly important in London, where patients might access several different sites for their care.

Results should be interpreted with caution because we partitioned data into subsets to construct life tables for subgroups, unlike in multivariable regression where adjusted estimates are the norm. We could not control for lifestyle factors that could be associated both with late treatment and with a poorer life expectancy, such as smoking or socioeconomic position. The estimates of life expectancy are based on extrapolations of the age and sex specific mortality rates observed during the study period in the actual cohort, which are then applied to a hypothetical cohort as if they applied to individuals throughout their lives. The validity of this assumption could be greatest for patients with persistently suppressed viral loads.

\section{Implications of findings}

The improvement in life expectancy since 1996 is probably due to several factors: a greater proportion of patients with high CD4 counts, better antiretroviral therapy, changing demographics of the population of patients (namely, more women and immigrants from sub-Saharan Africa), and an upward trend in the population life expectancy. The patients treated in earlier years started therapy with more advanced HIV disease, were more likely to develop drug resistant HIV because of pre-treatment with one or two antiretroviral drugs, ${ }^{22}$ and received regimens that were inferior to those currently prescribed in terms of viral suppression, pill burden, toxicity, and serious adverse effects. ${ }^{4}$ Improvements in treatment are unlikely to be only pharmacological: increasing experience among physicians could also have affected survival. ${ }^{23}$ Non-adherence to treatment can result in the development of drug resistance, which limits the number of treatment options available to patients.

Interruptions to treatment are associated with increased risk of virological rebound and serious non-AIDS events, as reported by the Strategies for Management of Anti-Retroviral Therapy (SMART) trial. ${ }^{24}$ Interrupting treatment probably became less common after the results of the trial were reported, which could have contributed to the increase in life expectancy after $2006 .{ }^{25}$ Modern first line regimens are more robust than earlier regimens. ${ }^{26}$ There has been a decline in transmission of drug resistant virus, ${ }^{27}$ and adherence has been improved by once daily treatment and coformulation of medications, all of which contribute to better virological control and, ultimately, greater life expectancy.

The higher life expectancy in women in the general population is magnified in those with HIV. This could be because of earlier diagnosis through screening in antenatal clinics $^{28}$ before women have a low CD4 count, late presentation in men, ${ }^{29}$ or sex differences in lifestyle factors that are exaggerated in patients (for example, smoking, alcohol, and drug misuse are common in men who have sex with men but not in women from sub-Saharan Africa). Alternatively, there could be bias from loss to follow-up and consequent under-ascertainment of death in women. It is important to further understand this discrepancy and formulate policy to ensure that there are equal opportunities to achieve the same outcome in men and women.

The data on life expectancy stratified by CD4 count show that an important driver of the lower life expectancy in people with HIV compared with the general population is that patients started treatment at a lower CD4 count than recommended by guidelines. ${ }^{17}$ At the start of treatment, mortality is highest for those with lowest CD4 count, ${ }^{7}$ and even in those who survive the first three years of treatment, CD4 count at start of antiretroviral therapy remains prognostic..$^{30} \mathrm{~A}$ review of deaths among treated patients with HIV in the Royal Free Hospital in London from 1998 to 2003 cited late presentation, delayed uptake of antiretroviral therapy, and previous use of treatment combinations now viewed as suboptimal as contributory factors. ${ }^{31}$ A high proportion of patients in UK CHIC started treatment with CD4 count $<200$ cells $/ \mathrm{mm}^{3}{ }^{32}$ This proportion is consistent with that seen in many other European settings, where many people do not receive a diagnosis of HIV infection until their CD4 counts have already fallen to low levels. Late presentation, however, is only a partial explanation: patients, particularly if they have no symptoms, might have delayed starting treatment because of a reluctance to embark on a lifelong commitment to take antiretroviral drugs, many of which have a poor toxicity/tolerability profile. Before starting treatment, many patients had substantial gaps between CD4 assessments, reflecting irregular clinic attendance. ${ }^{32}$

In addition to deaths from AIDS defining diagnoses, people with HIV experience higher rates of non-AIDS deaths than the general population, which could be due to HIV infection, adverse events associated with treatment for HIV, or lifestyle factors. The prevalence of smoking, drug misuse, and alcoholism are all higher among people with HIV, which leads to increased deaths from cardiovascular disease, cancer, liver disease, suicide, 
overdose, and injury. We were unable to account for lifestyle factors or cause of death in this analysis.

\section{Comparison with other studies}

The life expectancy in our study is somewhat lower than that estimated in a study by the Antiretroviral Therapy Cohort Collaboration, although the increase in life expectancy of 13 years between 1996 and 2005 is similar. ${ }^{16}$ The lower life expectancy in UK CHIC could be because of the inclusion of patients previously treated with one or two antiretroviral drugs or more complete ascertainment of death. Estimates of life expectancy and trends over time based on a study in Denmark are similar to our estimates. ${ }^{12}$ Compared with the general population, standardised mortality rates for people with HIV treated for at least six months have been estimated to vary from 1.05 (95\% confidence interval 0.82 to 1.35 ) to 73.7 (46.4 to 116.9), depending on transmission risk group and clinical stage at baseline and CD 4 count and viral load at six months. ${ }^{3}$ Recent studies have estimated life expectancy or standardised mortality rates for highly selected groups of people with HIV that approach those of the comparator uninfected population. For example, in the Netherlands the number of years of life lost by asymptomatic patients with a recent diagnosis varied from 0.4 years in those aged 25 at diagnosis to 1.4 years in those aged $55 .^{33}$ In this group of patients, the median CD4 cell count was 480 cells $/ \mathrm{mm}^{3}$ (interquartile range $360-650$ ). The Collaboration of Observational HIV Epidemiological Research in Europe (COHERE) found that death rates among men, but not women, with CD 4 counts $>500$ cells $/ \mathrm{mm}^{3}$ reached those of the matched general population after at least three years' receipt of antiretroviral therapy with counts above that threshold. ${ }^{34}$ These studies show what can be achieved if patients receive an early diagnosis, avoid compromising their immune system and the attendant morbidities ${ }^{35}$ and are successfully treated to restore their CD4 count to a level approaching normality.

\section{Conclusions}

Life expectancy among people with HIV has considerably improved in the UK between 1996 and 2008, and we should expect further improvements for patients starting antiretroviral therapy now with improved modern drugs and new guidelines recommending earlier treatment. Our study shows the longevity of patients who started antiretroviral therapy with a CD4 count of 200-350 cells $/ \mathrm{mm}^{3}$. These data can be incorporated into models for life insurance, pensions, and healthcare planning, but most of all communicated to patients to help them manage their lives better. Furthermore, the clear impact of low CD4 count on life expectancy implies that it is particularly important to diagnose HIV infection at an early stage. This would benefit both patients and healthcare systems as the patient would experience increased life expectancy and the healthcare system a reduction in the costs associated with lower CD4 count at diagnosis, including hospital treatment or admission, or both. Our findings strongly support the concept of more widespread testing for HIV, especially initiatives to achieve universal testing. It is also of clear benefit to the patient to have the prognosis made in terms of their life expectancy, and this might have considerable impact on patients' uptake of testing.

This work was presented in part at the Tenth International Congress on Drug Therapy in HIV Infection Glasgow, UK, 7-11 November 2010. ${ }^{36}$

Contributors: MM conceived the study design, analysed the data, and wrote the first draft of the paper. MG contributed to study design and writing the first draft of the paper. LB was responsible for data management. All clinician authors were involved in data collection at study sites. All authors contributed to data interpretation and the final text. CS is principal investigator of UK CHIC Study and coordinated the study. MM, CS, and LB had full access to all the data in the study. MM had the final responsibility for the decision to submit for publication and is guarantor.

Funding: The UK CHIC Study is funded by the UK Medical Research Council (grant G0000199 and G0600337). MM is also funded by the UK Medical Research Council (grant G0700820). The views expressed in this manuscript are those of the researchers and not necessarily those of the Medical Research Council. The funders had no role in carrying out the study or in the decision to submit the manuscript for publication.

Competing interests: All authors have completed the ICMJE uniform disclosure form at www.icmje.org/coi_disclosure.pdf (available on request from the corresponding author) and declare: no support from any organisation for the submitted work; no financial relationships with any organisations that might have an interest in the submitted work in the previous three years; no other relationships or activities that could appear to have influenced the submitted work.

Ethical approval: The project was approved by a multicentre research ethics committee and by local ethics committees.

Data sharing: No additional data available.

1 Mocroft A, Vella S, Benfield TL, Chiesi A, Miller V, Gargalianos P, et al. Changing patterns of mortality across Europe in patients infected with HIV-1. Lancet 1998;352:1725-30.

2 Egger M, Hirschel B, Francioli P, Sudre P, Wirz M, Flepp M, et al. Impact of new antiretroviral combination therapies in HIV infected patients in Switzerland: prospective multicentre study. BMJ 1997;315:1194-9.

3 Zwahlen M, Harris RJ, Hogg R, Costagliola D, May M, de Wolf F, et al, and Antiretroviral Therapy Cohort Collaboration. Mortality of HIV-infected patients starting potent antiretroviral therapy: comparison with the general population in eight industrialized countries. Int $J$ Epidemiol 2009;38:1624-33.

4 Jaggy C, von Overbeck J, Ledergerber B, Schwarz C, Egger M, Rickenbach M, et al. Mortality in the Swiss HIV Cohort Study (SHCS) and the Swiss general population. Lancet 2003;362:877-8.

5 Keiser O, Taffe P, Zwahlen M, Battegay M, Bernasconi E, Weber R, et al. All cause mortality in the Swiss HIV Cohort Study from 1990 to 2001 in comparison with the Swiss population. AIDS 2004:18:1835-43.

6 Bhaskaran K, Hamouda O, Sannes M, Boufassa F, Johnson AM, Lambert PC, et al. Changes in the risk of death after HIV seroconversion compared with mortality in the general population. JAMA 2008;300:51-9.

7 May M, Sterne JA, Sabin C, Costagliola D, Justice AC, Thiebaut R, et al. Prognosis of HIV-1-infected patients up to 5 years after initiation of HAART: collaborative analysis of prospective studies. AIDS 2007;21:1185-97.

8 Cooper DA. Life and death in the CART era. Lancet 2008:372:266-7.

9 World Health Organization. Annex table 2: deaths by cause, sex and mortality stratum in WHO regions, estimates for 2002 . The world health report 2004—changing history. WHO, 2004.

10 Braitstein P, Brinkhof MW, Dabis F, Schechter M, Boulle A, Miotti P, et al. Mortality of HIV-1-infected patients in the first year of antiretroviral therapy: comparison between low-income and high-income countries. Lancet 2006:367:817-24.

11 UK Collaborative HIV Cohort (UK CHIC) Study. The creation of a large UK-based multicentre cohort of HIV-infected individuals: the UK Collaborative HIV Cohort (UK CHIC) Study. HIV Med 2004;5:115-24.

12 Lohse N, Hansen AB, Pedersen G, Kronborg G, Gerstoft J, Sorensen HT, et al. Survival of persons with and without HIV infection in Denmark, 1995-2005. Ann Intern Med 2007:146:87-95.

13 Van Sighem A, Danner S, Ghani AC, Gras L, Anderson RM, de Wolf F. Mortality in patients with successful initial response to highly active antiretroviral therapy is still higher than in non-HIV-infected individuals. J Acquir Immune Defic Syndr 2005;40:212-8.

14 Losina E, Schackman BR, Sadownik SN, Gebo KA, Walensky RP, Chiosi JJ, et al. Racial and sex disparities in life expectancy losses among HIV-infected persons in the united states: impact of risk behavior, late initiation, and early discontinuation of antiretroviral therapy. Clin Infect Dis 2009;49:1570-8.

15 Harrison KM, Song R, Zhang X. Life expectancy after HIV diagnosis based on national HIV surveillance data from 25 states, United States. J Acquir Immune Defic Syndr 2010;53:124-30.

16 ART-CC. Life expectancy of individuals on combination antiretroviral therapy in high-income countries: a collaborative analysis of 14 cohort studies. Lancet 2008;372:293-9.

17 Gazzard BG, Anderson J, Babiker A, Boffito M, Brook G, Brough G, et al. British HIV Association guidelines for the treatment of HIV-1-infected adults with antiretroviral therapy 2008. HIV Med 2008;9:563-608.

18 Gardner JW, Sanborn JS. Years of potential life lost (YPLL) — what does it measure? Epidemiology 1990;1:322-9.

19 Pozniak A, Gazzard B, Anderson J, Babiker A, Churchill D, Collins S, et al. British HIV Association (BHIVA) guidelines for the treatment of HIV-infected adults with antiretroviral therapy. HIV Med 2003;4(suppl 1):1-41.

20 Health Protection Agency. Survey of prevalent HIV infections diagnosed (SOPHID) data table 2009. 2011. www.hpa.org.uk/Topics/InfectiousDiseases/InfectionsAZ/HIV/ AccessingHIVCare/hivsti sophid NumbersaccessingHIVcareNationalOverview/.

21 Hill T, Bansi L, Sabin C, Phillips A, Dunn D, Anderson J, et al. Data linkage reduces loss to follow-up in an observational HIV cohort study. J Clin Epidemiol 2010;63:1101-9. 


\section{What is already known on this topic}

Life expectancy is an important health indicator that informs decisions by individuals and public policy makers

Life expectancy in people treated for HIV infection in industrialised countries has been estimated to be much lower than that of the

general population

\section{What this study adds}

In the UK, life expectancy (at the exact age of 20) in those treated for HIV infection has increased by 15 years over the period 1996-2008, but is still about 13 years less than that of the UK population

The higher life expectancy of women compared with men is magnified among people with HIV

There is a need to identify people with HIV early in the course of disease to avoid the large negative impact that starting antiretroviral therapy at a CD4 count below $200 \mathrm{cells} / \mathrm{mm}^{3}$ has on life expectancy

22 Bansi L, Sabin C, Delpech V, Hill T, Fisher M, Walsh J, et al. Trends over calendar time in antiretroviral treatment success and failure in HIV clinic populations. HIV Med 2010;11:432-8.

23 Kitahata MM, Van Rompaey SE, Dillingham PW, Koepsell TD, Deyo RA, Dodge W, et al. Primary care delivery is associated with greater physician experience and improved survival among persons with AIDS. J Gen Intern Med 2003:18:95-103.

24 El-Sadr WM, Grund B, Neuhaus J, Babiker A, Cohen CJ, Darbyshire J, et al. Risk for opportunistic disease and death after reinitiating continuous antiretroviral therapy in patients with HIV previously receiving episodic therapy: a randomized trial. Ann Intern Med 2008;149:289-99.

25 Bansi LK, Benzie AA, Phillips AN, Portsmouth S, Hill T, Leen C, et al. Are previous treatment interruptions associated with higher viral rebound rates in patients with viral suppression? AIDS 2008;22:349-56.

26 Lodwick RK, Smith CJ, Youle M, Lampe FC, Tyrer M, Bhagani S, et al. Stability of antiretroviral regimens in patients with viral suppression. AIDS 2008;22:1039-46.

27 UK Collaborative Group on HIV Drug Resistance, UK Collaborative HIV Cohort Study, UK Register of HIV Seroconverters. Evidence of a decline in transmitted HIV-1 drug resistance in the United Kingdom. AIDS 2007;21:1035-9.

28 Chadborn TR, Delpech VC, Sabin CA, Sinka K, Evans BG. The late diagnosis and consequent short-term mortality of HIV-infected heterosexuals (England and Wales, 2000-2004). AIDS 2006;20:2371-9.

29 Easterbrook PJ, Phillips AN, Hill T, Matthias R, Fisher M, Gazzard B, et al. Patterns and predictors of the use of different antiretroviral drug regimens at treatment initiation in the UK. HIV Med 2008:9:47-56.

30 ART-CC. Prognosis of patients treated with combined antiretroviral therapy from 36 months after initiation, according to current and previous CD4 cell count and plasma HIV-1 RNA measurements. AIDS 2009;23:2199-208.
31 Sabin CA, Smith CJ, Youle M, Lampe FC, Bell DR, Puradiredja D, et al. Deaths in the era of HAART: contribution of late presentation, treatment exposure, resistance and abnormal laboratory markers. AIDS 2006;20:67-71.

32 Stohr W, Dunn D, Porter K, Hill T, Gazzard B, Walsh J, et al. CD4 cell count and initiation of antiretroviral therapy: trends in seven UK centres, 1997-2003. HIV Med 2007;8:135-41.

33 Van Sighem Al, Gras LA, Reiss P, Brinkman K, de Wolf F. Life expectancy of recently diagnosed asymptomatic HIV-infected patients approaches that of uninfected individuals. AIDS 2010;24:1527-35.

34 Lewden C, Mortality Working Group of COHERE. Time with CD4 cell count above 500 cells $/ \mathrm{mm}^{3}$ allows HIV-infected men, but not women, to reach similar mortality rates to those of the general population: a 7-year analysis. Abstract 527. 17th Conference on Retroviruses and Opportunistic Infections (CROI), San Francisco, 2010.

35 Marin B, Thiebaut R, Bucher HC, Rondeau V, Costagliola D, Dorrucci M, et al. Non-AIDS-defining deaths and immunodeficiency in the era of combination antiretroviral therapy. AIDS 2009;23:1743-53.

36 May M, Gompels M, Sabin CA. O233 Impact on life expectancy of late diagnosis and treatment of HIV-1 infected individuals: UK CHIC. J Int AIDS Soc 2010;13(suppl 4):O27

\section{Accepted: 24 August 2011}

\section{Cite this as: BMJ 2011;343:d6016}

This is an open-access article distributed under the terms of the Creative Commons Attribution Non-commercial License, which permits use, distribution, and reproduction in any medium, provided the original work is properly cited, the use is non commercial and is otherwise in compliance with the license. See: http://creativecommons.org/licenses/by$\mathrm{nc} / 2.0 /$ and http://creativecommons.org/licenses/by-nc/2.0/legalcode. 


\section{Tables}

Table 1| Characteristics of patients at start of combination antiretroviral therapy (by period of initiation of treatment $(n=17661)(P<0.001$ for all variables). Figures are numbers (percentage) of patients unless stated otherwise

\begin{tabular}{|c|c|c|c|c|c|}
\hline Variable & $1996-9(n=5849)$ & $2000-2(n=3609)$ & $2003-5(n=4180)$ & $2006-8(n=4023)$ & $1996-2008(n=17661)$ \\
\hline \multicolumn{6}{|l|}{ Age (years): } \\
\hline Median (IQR) & $36(31-42)$ & $36(32-42)$ & $37(32-43)$ & $38(32-44)$ & $37(32-43)$ \\
\hline $16-29$ & $1049(18)$ & $644(18)$ & $694(17)$ & $661(16)$ & $3048(17)$ \\
\hline $30-39$ & $3019(52)$ & $1826(51)$ & $1989(48)$ & $1744(43)$ & $8578(49)$ \\
\hline $40-49$ & $1262(22)$ & $820(23)$ & $1088(26)$ & $1202(30)$ & $4372(25)$ \\
\hline $50-59$ & $430(7.4)$ & $243(6.7)$ & $311(7.4)$ & $314(7.8)$ & $1298(7.4)$ \\
\hline$\geq 60$ & $89(1.5)$ & $76(2.1)$ & $98(2.3)$ & $102(2.5)$ & $365(2.1)$ \\
\hline Men & $4809(82)$ & $2548(70)$ & $2949(71)$ & $2996(75)$ & $13302(75)$ \\
\hline White & $4085(70)$ & $1823(50)$ & $2097(50)$ & $2193(55)$ & $10198(58)$ \\
\hline \multicolumn{6}{|l|}{ Risk factor for transmission: } \\
\hline $\begin{array}{l}\text { Men who have sex with } \\
\text { men }\end{array}$ & $3835(66)$ & $1697(47)$ & $2067(49)$ & $2025(50)$ & $9624(54)$ \\
\hline Heterosexual & $1517(26)$ & $1593(44)$ & $1863(45)$ & $1521(38)$ & $6494(37)$ \\
\hline Other or unknown & $497(8.5)$ & $319(8.8)$ & $250(6.0)$ & $477(11.9)$ & $1543(8.7)$ \\
\hline \multicolumn{6}{|l|}{ CD4 cell count $\left(\text { cells } / \mathrm{mm}^{3}\right)^{*}$ : } \\
\hline Median (IQR) & $140(50-230)$ & $149(61-225)$ & $174(90-235)$ & $200(113-263)$ & $166(75-241)$ \\
\hline$<100$ & $1799(39)$ & $1026(35)$ & $955(27)$ & $805(22)$ & $4585(31)$ \\
\hline $100-199$ & $1314(28)$ & $943(32)$ & $1183(33)$ & $994(27)$ & $4434(30)$ \\
\hline $200-350$ & $1537(33)$ & $982(33)$ & $1436(40)$ & $1894(51)$ & 5849 (39) \\
\hline AIDS stage $\mathrm{C} \dagger$ diagnosis & $2179(37)$ & $1007(28)$ & $828(20)$ & $576(14)$ & $4590(26)$ \\
\hline \multicolumn{6}{|c|}{ HIV-1 RNA level $\left(\log _{10}\right.$ copies $\left./ \mathrm{mL}\right) \ddagger$ : } \\
\hline Median (IQR) & $4.9(4.1-5.4)$ & $5.0(4.3-5.5)$ & $4.9(4.2-5.4)$ & $4.7(4.0-5.2)$ & $4.9(4.1-5.4)$ \\
\hline$<4.00$ & $873(22)$ & $495(17)$ & $739(21)$ & $958(26)$ & $3065(22)$ \\
\hline $4.00-4.99$ & $1364(35)$ & $997(35)$ & $1208(34)$ & $1436(38)$ & $5005(35)$ \\
\hline$\geq 5.00$ & $1697(43)$ & $1397(48)$ & $1627(46)$ & $1341(36)$ & $6062(43)$ \\
\hline Naive at start of triple ART§ & $3145(54)$ & $3281(91)$ & $4014(96)$ & $3853(96)$ & $14293(81)$ \\
\hline \multicolumn{6}{|l|}{ Initial drug regimen: } \\
\hline PI based & $3142(54)$ & $494(14)$ & $819(20)$ & $1207(30)$ & $5662(32)$ \\
\hline NNRTI based & $1777(30)$ & $2387(66)$ & $3019(72)$ & $2586(64)$ & $9769(55)$ \\
\hline Triple NRTI & $292(5.0)$ & $234(6.5)$ & $82(2.0)$ & $25(0.6)$ & $633(3.6)$ \\
\hline Four or more drugs & $359(6.1)$ & $457(13)$ & $190(4.6)$ & $128(3.2)$ & $1134(6.4)$ \\
\hline Other or unknown & $279(4.8)$ & $37(1.0)$ & $70(1.7)$ & $77(1.9)$ & $463(2.6)$ \\
\hline
\end{tabular}

$\mathrm{IQR}=$ interquartile range; $\mathrm{ART}=$ =antiretroviral therapy; $\mathrm{PI}=$ protease inhibitor; $\mathrm{NNRTI}=$ non-nucleoside reverse transcriptase inhibitor; $\mathrm{NRTI}=$ nucleoside reverse transcriptase inhibitor.

*Available for 14868 (84\%) patients.

†Center for Disease Control (CDC) clinical stage.

$\ddagger$ Available for 14132 (80\%) patients.

§Previous exposure to one or two antiretroviral drugs before start of combination therapy. 
Table 2| Health indicators for overall treated population of patients (age $\geq 20$ ) who started antiretroviral therapy in 1996-2008 by period of follow-up

\begin{tabular}{|c|c|c|c|c|c|}
\hline Measure & $1996-9$ & $2000-2$ & 2003-5 & 2006-8 & 1996-2008 \\
\hline No of patients in follow-up & 5471 & 8493 & 12029 & 15152 & 17661 \\
\hline No of deaths & 271 & 308 & 341 & 328 & 1248 \\
\hline \multicolumn{6}{|l|}{ Mortality rates per 1000 person years $(95 \% \mathrm{Cl})$ : } \\
\hline Overall & $26.8(23.7$ to 30.1$)$ & $16.3(14.6$ to 18.3$)$ & $12.2(11.0$ to 13.6$)$ & $9.5(8.6$ to 10.6$)$ & $13.7(12.9$ to 14.5$)$ \\
\hline Age $20-44$ & 22.7 (19.5 to 26.2$)$ & $14.5(12.7$ to 16.7$)$ & 10.0 (8.6 to 11.5$)$ & 7.5 (6.4 to 8.8$)$ & 11.7 (10.9 to 12.6$)$ \\
\hline Potential years of life lost for ages 20-64 (per 1000 person years) & 611.3 & 365.5 & 248.5 & 175.1 & 285.3 \\
\hline \multicolumn{6}{|l|}{ Life expectancy (years): } \\
\hline At exact age $20\left(\mathrm{SE}^{\star}\right)$ & $30.0(1.2)$ & $39.4(1.2)$ & $43.1(1.0)$ & $45.8(1.7)$ & $41.1(0.5)$ \\
\hline At exact age $35\left(\mathrm{SE}^{\star}\right)$ & $20.0(0.6)$ & $28.2(0.6)$ & $31.6(0.5)$ & $35.6(0.5)$ & $30.8(0.2)$ \\
\hline$\%$ surviving from 20 to 44 & 60.8 & 74.7 & 81.6 & 82.3 & 77.3 \\
\hline
\end{tabular}


Table 3| Health indicators stratified by sex for treated population who started antiretroviral therapy 1996-2008 ( $n=17$ 661) and for the UK population (1996-2006)

\begin{tabular}{|c|c|c|c|c|}
\hline \multirow[b]{2}{*}{ Measure } & \multicolumn{2}{|c|}{ People with HIV (1996-2008) } & \multicolumn{2}{|c|}{ UK population (1996-2006) } \\
\hline & Men & Women & Men & Women \\
\hline No of patients & 13302 & 4359 & - & - \\
\hline No of deaths & 1058 & 190 & - & - \\
\hline \multicolumn{5}{|l|}{ Mortality rates per 1000 person years $(95 \% \mathrm{Cl})$ : } \\
\hline Overall & $13.7(12.9$ to 14.5$)$ & $9.4(8.1$ to 10.8$)$ & 13.4 & 13.7 \\
\hline Age 20-44 & $11.7(10.9$ to 12.6$)$ & 8.9 (7.6 to 10.5$)$ & 1.2 & 0.6 \\
\hline Potential years of life lost for ages 20-64 (per 1000 person years) & 291.4 & 229.3 & 35.4 & 18.9 \\
\hline \multicolumn{5}{|l|}{ Life expectancy (years): } \\
\hline At exact age $20\left(\mathrm{SE}^{\star}\right)$ & $39.5(0.45)$ & $50.2(0.45)$ & 57.8 & 61.6 \\
\hline At exact age $35\left(\mathrm{SE}^{\star}\right)$ & $30.1(0.24)$ & $37.7(0.24)$ & 43.5 & 46.9 \\
\hline$\%$ surviving from 20 to 44 & 74.6 & 84.3 & 97.0 & 98.4 \\
\hline
\end{tabular}


Table 4 Health indicators for patients who had not previously received antiretroviral drugs and started combination antiretroviral therapy in 2000-8 stratified by CD4 cell count at start of treatment $(n=9657)$

\begin{tabular}{|c|c|c|c|}
\hline \multirow[b]{2}{*}{ Measure } & \multicolumn{3}{|c|}{ CD4 cell count } \\
\hline & $<100$ cells $/ \mathrm{mm}^{3}$ & $100-199$ cells $/ \mathrm{mm}^{3}$ & $200-350$ cells $/ \mathrm{mm}^{3}$ \\
\hline No of patients & 2689 & 2940 & 4028 \\
\hline No of deaths & 173 & 101 & 75 \\
\hline \multicolumn{4}{|l|}{ Mortality rates per 1000 person years $(95 \% \mathrm{Cl})$ : } \\
\hline Overall & $16.7(14.4$ to 19.4$)$ & 9.2 (7.6 to 11.3$)$ & $5.9(4.7$ to 7.4$)$ \\
\hline Age $20-44$ & $14.5(12.0$ to 17.6$)$ & $6.8(5.2$ to 8.9$)$ & 5.1 (3.8 to 6.8$)$ \\
\hline Potential years of life lost for ages $20-64$ (per 1000 person years) & 357.7 & 184.9 & 120.5 \\
\hline \multicolumn{4}{|l|}{ Life expectancy (years): } \\
\hline At exact age $20\left(\mathrm{SE}^{\star}\right)$ & $37.9(1.3)$ & $41.0(2.2)$ & $53.4(1.2)$ \\
\hline At exact age $35\left(\mathrm{SE}^{\star}\right)$ & $27.0(0.7)$ & $30.4(0.7)$ & $40.5(1.1)$ \\
\hline$\%$ surviving from 20 to 44 & 75.0 & 82.7 & 89.2 \\
\hline
\end{tabular}




\section{Figures}

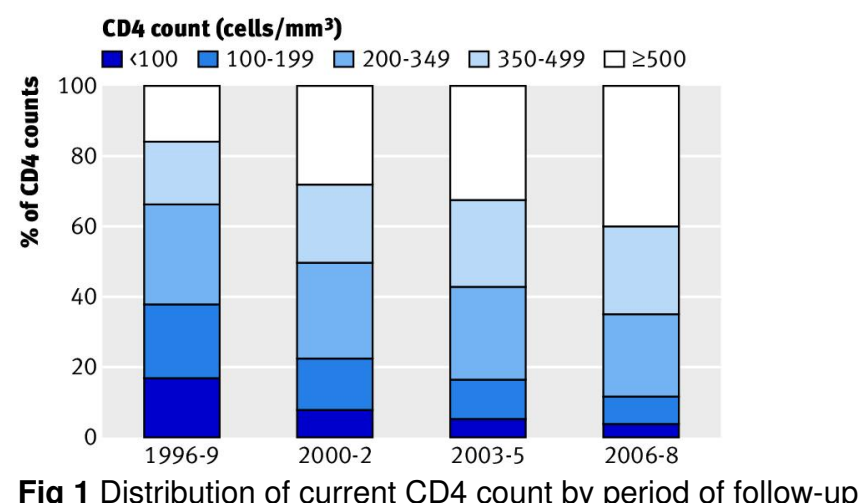

Fig 1 Distribution of current CD4 count by period of follow-up



Fig 2 Life expectancy from age 20-65 of people who started antiretroviral therapy in 2000-8 by CD4 cell count group at start of antiretroviral therapy compared with that of UK population (2000-6 women and men) 